\section{Whiplash and the Turtle}

To the Editor:

Behold the turtle. He makes progress only when he sticks his neck out. - James Bryant Conant

In his response to our editorial ${ }^{1}$, Harth ${ }^{2}$ reveals something that is known to any reader of the scientific literature: all studies have flaws. In fact, without the joke, his editorial could be 4 words long: all studies have flaws. Thus, he himself cites Karnezis, et $a l^{3}$, but this was a study of a sample of litigants, so select a population that generalizing their findings to the clinical population is impossible, except to say that in Greece, $40 \%$ of litigants recover while they are still litigants! Despite flaws in every study, medical science advances, our capacity to manage complex medical problems advances, and a willingness to explore new approaches to clinical problems in chronic pain continues. This is not surprising; if rheumatologists failed to incorporate new data into their disease models, no advances in our understanding of the disorders we treat could ever take place.

Perhaps Harth does not utilize research data in developing models of illness in the same way we do. Our approach, described elsewhere ${ }^{4}$, is Tukeyan: All studies are flawed; the practical question is how flawed do they have to be to not be useful. That a study or article has flaws does not make its conclusions wrong. A critical review of methodologic flaws should represent an honest effort to encourage a higher scientific effort in studies, particularly on controversial topics. Such reviews should never be used to merely discard disconcerting data rather than discarding a precious model. We believe Harth is encouraging the latter behavior.
Finally, given the failure of an "injury-based" model to provide meaningful solutions to the whiplash problem over many decades, we fail to see how maintaining that approach is useful, and why exploration of social interventions is not useful. Progress requires new ideas, even controversial ones, to be explored and examined with the risk that new ideas may actually make a difference.

ANTHONY S. RUSSELL, MD, FRCPC, Rheumatic Disease Unit, University of Alberta Hospital, Department of Medicine, 562 Heritage Medical Research Centre, Edmonton, Alberta T6G 2S2, Canada; ROBERT FERRARI, MD, FRCPC, University of Alberta Hospital, Department of Medicine, Edmonton, Alberta, Canada Address reprint requests to Dr. Russell; e-mail: as.russell@ualberta.ca

\section{REFERENCES}

1. Russell AS, Ferrari R. Whiplash: social interventions and solutions [editorial]. J Rheumatol 2008;35:2300-2.

2. Harth M. Stopping late whiplash: which way to utopia? [editorial]. J Rheumatol 2008;35:2303-5.

3. Karnezis IA, Drosos GI, Kazakos KI. Factors affecting the timing of recovery from whiplash neck injuries: study of a cohort of 134 patients pursuing litigation. Arch Orthop Trauma Surg 2007;127:633-6.

4. Ferrari R, Russell AS. Whiplash: heading for a higher ground. Spine 1999;24:97-8.

J Rheumatol 2009;36:6; doi:10.3899/jrheum.081332 